\title{
Historia de la elaboración de la periodización específica para el voleibol: una revisión
}

\author{
History of the elaboration of the specific periodization for the \\ volleyball: a review
}

Nelson Kautzner Marques Junior ${ }^{1,2}$

Revisión

${ }^{1}$ Mestre em Ciência da Motricidade Humana pela UCB, Rio de
Janeiro, Brasil.
${ }^{2}$ Membro do Comitê Científico da Revista Observatorio del Deporte,
Universidade de Los Lagos, Santiago do Chile.

Resumen

Objetivo: Fue necesario explicar la historia de la elaboración del contenido teórico de la periodización específica para el voleibol.

Método: El estudio de revisión se realizó en octubre de 2019 a febrero de 2020 y los artículos se recopilaron en Research Gate con la palabra clave periodização específica para o voleibol o specific periodization for the volleyball.

Resultados: Esta concepción consta de seis períodos. El período de los eventos que dieron lugar las primeras ideas sobre la elaboración de la concepción de periodización para el voleibol (de 1976 a 2010) se presentó la vida deportiva del creador de esta periodización y los estudios de educación física de este investigador que fueron importantes para generar los primeros ideas sobre esta periodización. El período de los primeros estudios teóricos de la concepción de periodización para el voleibol culminó con un artículo escrito en 2011 y 2014. Sin embargo, estas primeras ideas necesitaban más contenido, ocurriendo en 2016 y 2017 el período de elaboración de las escalas de percepción subjetiva (esfuerzo y dolor muscular) y de la estructuración de la carga de entrenamiento. El período de estructuración del entrenamiento fue de 2018 a 2020 y el autor explicó el entrenamiento con balón y la sesión física para el jugador de voleibol. El período de estructuración del entrenamiento fue de 2018 a 2020 y el autor explicó el entrenamiento con balón y la sesión física para el jugador de voleibol. El período de ideas para estudios científicos fue en 2019 porque se redactó una revisión con sugerencia de investigación para que los investigadores realicen investigaciones con esta concepción.

Conclusión: La historia de la teoría de la periodización específica para el voleibol es un estudio importante para que el entrenador comprenda la evolución de los estudios en esta concepción.

Palabras claves: Voleibol, rendimiento deportivo, habilidad motora, lesiones en deportistas.ı'

\section{Abstract}

Objective: It was necessary to explain the history of the elaboration of the theoretical content of the specific periodization for the volleyball.

Method: The review study was practiced in October 2019 to February 2020 and the articles were collected at Research Gate with the keyword periodização específica para o voleibol or specific periodization for the volleyball.

Results: This conception consists of six periods. The period of the events that caused the first ideas about the elaboration of a conception of periodization for the volleyball (of 1976 to 2010) was presented the sports life of the creator of this periodization and the physical education studies of this researcher that were important to generate the first ideas about this periodization. The period of the first theoretical studies of a conception of periodization for volleyball culminated with an article written in 2011 and 2014.

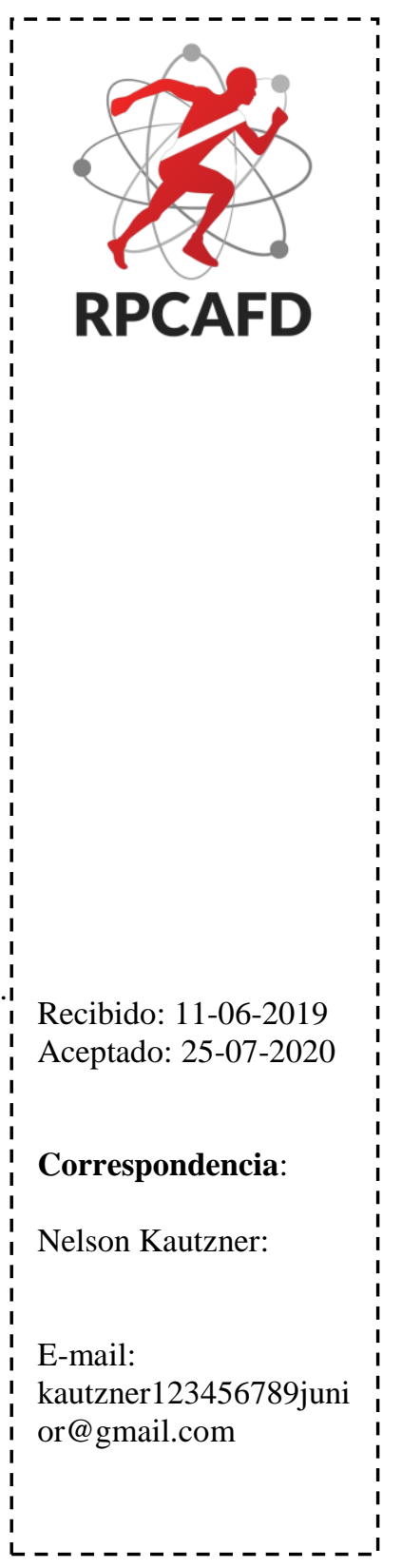

1090 
However, these first ideas needed more content, occurring in 2016 and 2017 the period of the elaboration of the scales of subjective perception (effort and muscle soreness) and the structuring of the training load. The training structuring period was from 2018 to 2020 and the author explained the ball training and the physical session for the volleyball player. The period of the ideas of the scientific studies was in 2019 because the author wrote a review with research suggestions for the researchers to conduct research with this conception.

Conclusion: The history of the theory of the specific periodization for the volleyball is an important study for the coach to understand the evolution of the researches in this conception.

Key words: Volleyball, athletic performance, motor skills, athletic injuries.

\section{Introdução}

A literatura do treinamento esportivo costumam dividir a periodização esportiva em três períodos, iniciando com o período empírico (da Grécia Antiga até 1950), seguindo com o período científico (1950 a 1977) e por último o período moderno (1978 até os nossos dias) $)^{1,2}$. Esses períodos aconteceram porque as concepções de periodização evoluíram ao longo dos anos conforme a necessidade da modalidade e de acordo com a evolução do conhecimento científico ${ }^{3,4}$. Portanto, estudar a história da periodização esportiva é uma tarefa relevante para os envolvidos no esporte de alto rendimento ${ }^{5,6}$.

Apesar da elaboração de diversos tipos de periodização no período moderno, alguns teóricos práticos consideraram as periodizações existentes inadequadas para os esportes coletivos porque a maioria das concepções são oriundas das modalidades individuais ${ }^{7,8}$. Entretanto, o voleibol possui características diferentes dos outros jogos esportivos coletivos, logo, merece ter um treinamento de acordo com as suas necessidades, precisa de um preparo psicológico conforme as exigências do esportista dessa modalidade, sendo indicado o uso das avaliações cineantropométricas e de scouts ou softwares de análise do jogo próprios para esse esporte ${ }^{9}$ e até é recomendado uma periodização somente para esse esporte ${ }^{10}$.

Porém, até 2010 não existia nenhum trabalho científico sugerindo uma periodização para o voleibo ${ }^{11,12}$, somente recomendando fazer adaptações das periodizações existentes para esse esporte ${ }^{13,14}$. Então, como Marques Junior vinha pesquisando a muito tempo sobre o voleibol $^{15,16}$, ele começou a escrever no início de 2000 as primeiras revisões sobre periodização para o jogador de voleibol ${ }^{17-19} \mathrm{e} o$ mesmo autor utilizou diversos tipos de periodização em um voleibolista ${ }^{20-23}$, esses acontecimentos propiciaram na estruturação de uma periodização para o voleibol.

Em 2011 esse pesquisador realizou o primeiro escrito de revisão sobre uma concepção para o voleibol, denominado de periodização específica para o voleibol ${ }^{24}$ e posteriormente foram conduzidos outros trabalhos sobre esse tema ${ }^{25-31}$. Os demais artigos de revisão sobre a periodização específica para o voleibol foram realizados para fundamentar cientificamente o conteúdo dessa concepção de periodização. Logo, torna interessante um artigo sobre a história da elaboração do conteúdo teórico dessa periodização. Para $\mathrm{Melo}^{32}$, o estudo do passado permite o entendimento do presente e é útil para o indivíduo compreender criticamente um conteúdo do esporte.

O objetivo da revisão foi de explicar a história da elaboração do conteúdo teórico da periodização específica para o voleibol.

\section{Método}

O estudo de revisão foi realizado em outubro de 2019 a fevereiro de 2020 e os artigos foram coletados no Research Gate com a palavra-chave periodização específica para $o$ voleibol ou specific periodization for the volleyball. Foram encontrados 8 artigos de revisão ${ }^{24-31}$ que fundamentaram essa teoria e foi utilizado um artigo que está sendo avaliando para publicação ${ }^{33}$. 


\section{Resultados}

1.1. Período dos acontecimentos que ocasionaram as primeiras ideias sobre a elaboração de uma concepção de periodização para o voleibol - 1976 a 2010

O idealizador dessa concepção de periodização foi praticante de jogos esportivos coletivos (ênfase no futebol e seus derivados) e de artes marciais (judô, capoeira e karatê shotokan) no período da infância e da préadolescência. Porém na adolescência, esse esportista desejava jogar futebol, mas como era difícil ingressar em um clube dessa modalidade e seu pai tinha sido levantador do América Football Club do Rio de Janeiro (veja esse clube

em

http://www.americario.com.br/2015/index.asp)

na década de 60 e ainda praticava voleibol de dupla na areia na rede de vôlei que fundou na Barra da Tijuca, no Rio de Janeiro, Brasil - foi fundada em 1981.

Então, esse adolescente foi encaminhado para o voleibol porque era mais fácil iniciar em um time. Isso aconteceu em 1986, esse jovem começou a treinar voleibol no Clube de Regatas do Flamengo (veja esse clube em https://www.flamengo.com.br/), mas foi "cortado" porque era muito fraco para essa modalidade, embora o que impressionava nesse pretende a jogador era o elevado salto vertical. Após esse ocorrido, ele começou a treinar no mirim da AABB Lagoa (mirim era a categoria do voleibol com idade de 13 a 14 anos, veja esse clube em http://www.aabb-rio.com.br/\#) com um dos maiores jogadores do Brasil que jogou na posição de levantador.

Esse levantador foi várias vezes campeão no Botafogo de Futebol e Regatas (veja esse clube em https://www.botafogo.com.br/) e conquistou a medalha de bronze em 1977 no $1^{\circ}$ Mundial Juvenil - categoria antes do voleibol profissional $^{34}$. Nesse mesmo ano, esse jovem voleibolista iniciou a prática do voleibol de dupla na areia na rede do seu pai. Posteriormente, jogou em outros clubes da iniciação do Rio de Janeiro (Hebraica Rio em $1987 \quad$ e $\quad 1988 \quad$ - $\quad$ veja em http://www.hebraicario.com.br/, Tijuca Tênis Clube em 1989 e 1990 - veja em https:/tijucatenis.com.br/) e começou a se dedicar integralmente ao voleibol de dupla na areia a partir de 1991. A figura 1 ilustra a iniciação esportiva do autor do artigo e seu pai após um campeonato de dupla na areia - foi um dos primeiros da praia da Barra da Tijuca.

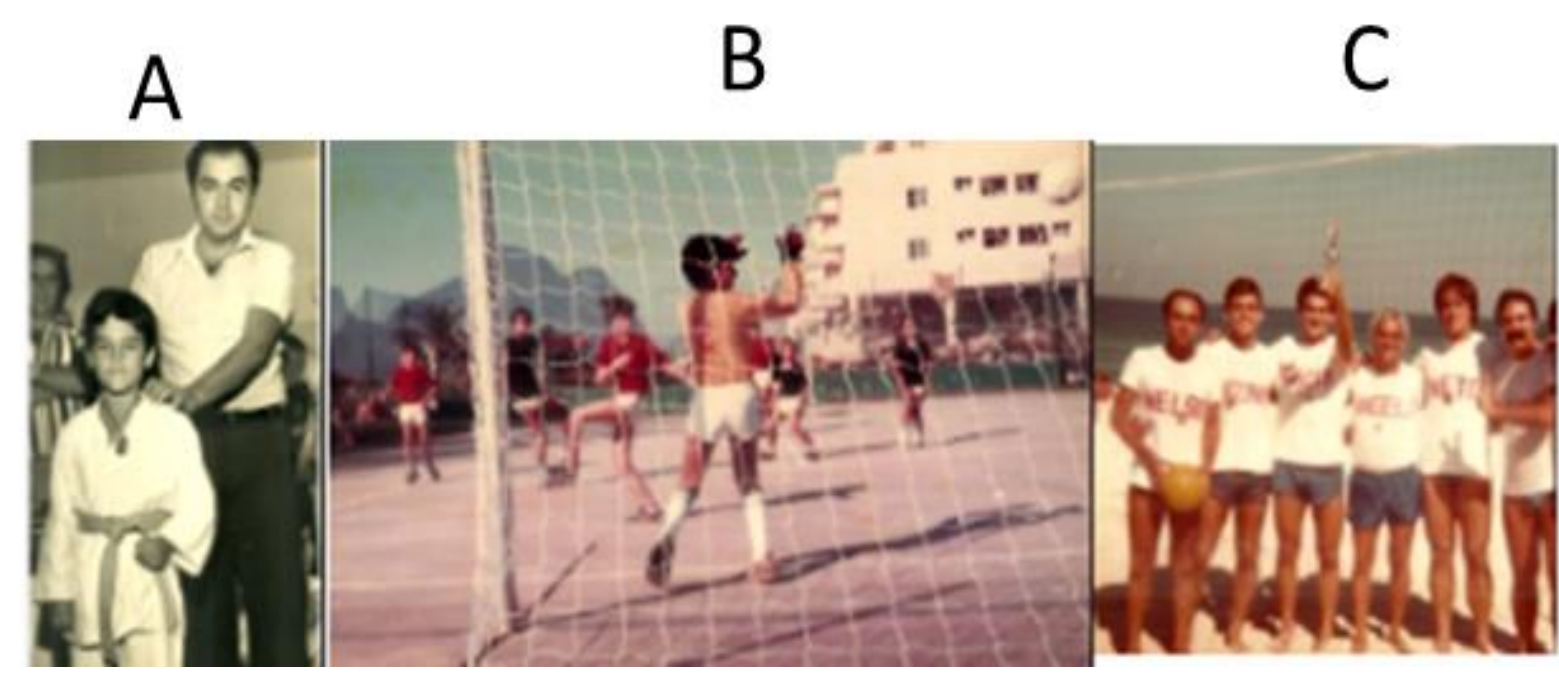

Figura 1. (A) Praticante de judô em 1977, (B) goleiro de futebol de salão em 1982 e (C) Nelson pai com a bola na mão, após o $3^{\circ}$ lugar com Luizinho no campeonato de dupla na areia em 1982 (Fotos do autor).

Durante a prática do voleibol de dupla na periodização ${ }^{20-23}$, isso foi importante para a areia, esse esportista foi atleta e treinador ao elaboração da periodização específica para o mesmo tempo (de 1991 até os anos 2000), como voleibol. Outro fator que contribuiu muito para ele utilizou no seu treino diversos tipos de estruturação dessa concepção foram os estudos 
da Educação Física da graduação, das três pós- do mestrado (ciência da motricidade humana). A graduações lato sensu (fisiologia do exercício e figura 2 ilustra o idealizador dessa periodização avaliação morfofuncional, musculação e em três momentos do voleibol. treinamento de força e treinamento desportivo) e

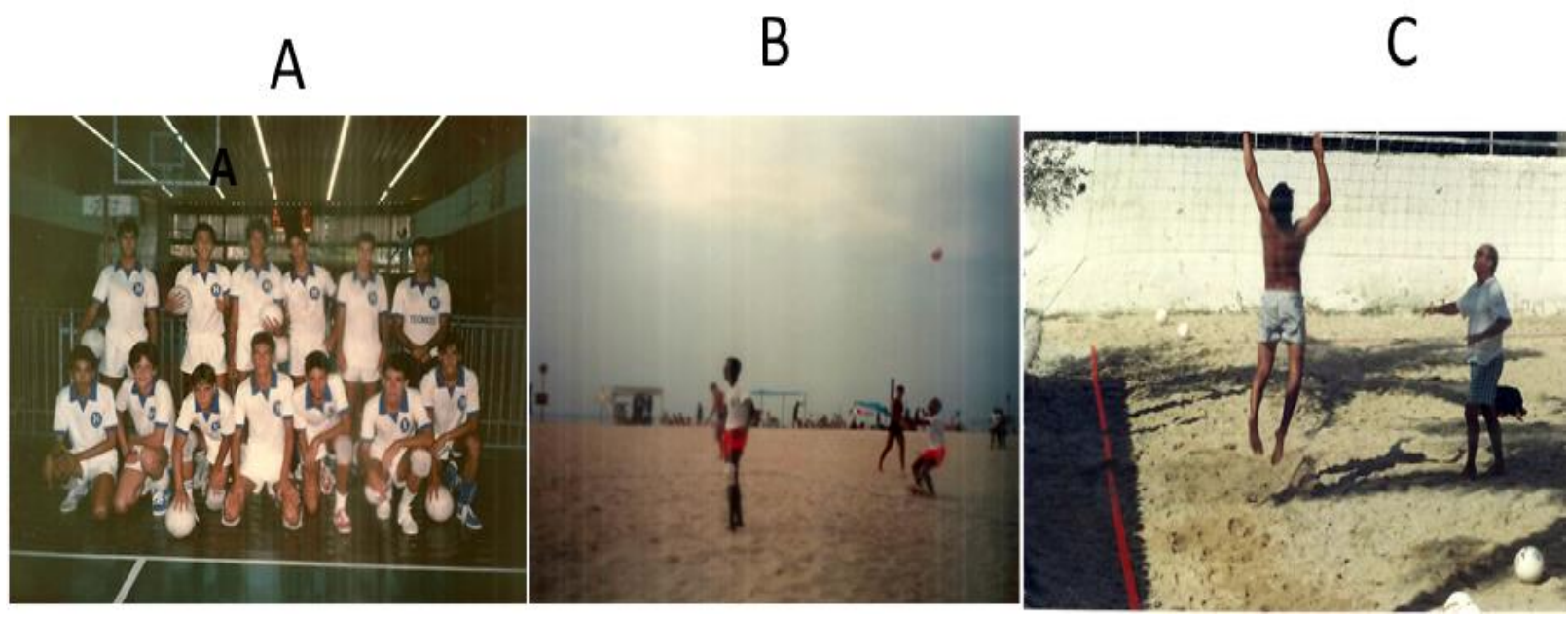

Figura 2. (A) Infanto juvenil da Hebraica do Rio de Janeiro em 1988 - da esquerda para direita é o quarto ajoelhado, (B) qualificatório para a Copa Puma em 1991 e (C) em 1998 no centro de treinamento de voleibol na areia e seu pai levantando (Fotos do autor).

Portanto, a estruturação da periodização específica para o voleibol foi através da união entre teoria e prática.

A definição dessa concepção é a seguinte: a periodização específica para o voleibol é um conteúdo do treinamento esportivo que objetiva organizar as sessões do treino técnico e tático e do trabalho físico com o intuito de proporcionar o sucesso esportivo através da regularidade competitiva e ocasionar um menor número de ocorrências de lesões durante a temporada de disputa.

O autor dessa teoria da periodização realizou algumas revisões sobre lesões no voleibol $^{35-37}$ com intuito de estruturar um treino com menor número de contusões nos voleibolistas. Então, essa preocupação levou esse pesquisador identificar os esforços dos fundamentos para os treinadores prescreverem as sessões do treino técnico e tático dosando o esforço dos exercícios subjetivamente $^{19}$. Logo, um esforço alto de uma tarefa do voleibol talvez pode ser mais propenso para gerar lesões. Mas um esforço leve do treino técnico e tático talvez possa acontecer ao contrário. Leonardo da Vinci realizou as seguintes conclusões sobre as contusões ${ }^{38}$ :

Leonardo da Vinci observou que "todas as lesões deixam dor na memória” e, para os atletas de nível olímpico, a memória com frequência não se limita à lesão propriamente dita, mas em geral inclui a dor permanente da oportunidade perdida (p. 397).

A lesão pode afetar o pico de desempenho pela perda de um milímetro ou de uma fração de segundo - e pode ser o fator decisivo na seleção para participar de uma equipe olímpica ou para ganhar uma medalha olímpica (p. 397).

Essas ideias em estruturar o treino com menor quantidade de lesões e de montar a sessão técnica e tática conforme os esforços dos fundamentos foi utilizado posteriormente pelo autor para elaborar os conteúdos da periodização específica para o voleibol.

\subsection{Período dos primeiros estudos teóricos de uma concepção de periodização para o voleibol -2011 e 2014}

A prática esportiva do voleibol, a dedicação aos estudos da Educação Física e o uso de diversos tipos de periodização culminaram com as primeiras ideias para elaborar uma concepção de periodização - ocorreu em janeiro de 2006, mas foi somente em 2011 que seu primeiro escrito foi publicado $^{24}$. 
O primeiro artigo da periodização específica para o voleibol informou que nessa concepção todo o treino é direcionado para o voleibol, não existindo preparação geral, somente treino específico para essa modalidade. A maioria das sessões dessa periodização merece ser realizada através do treino técnico e tático e quando for prescrito a preparação física, a sessão deve ser efetuada de preferência com o treino integrado. Esse treino integrado o jogador realiza a sessão com bola junto do treino físico e é indicado para fazer esse trabalho com o treino intermitente de máxima intensidade de Cometti ${ }^{39}$. Logo, o treino de força, de velocidade e de agilidade merece ser realizado preferencialmente na mesma sessão do treino técnico, do treino em situação de jogo e do treino de jogo do voleibol. Mas a sessão de flexibilidade e o trabalho aeróbio interferem em diversas capacidades motoras veja isso em Marques Junior ${ }^{40,41}$, sendo recomendado pelo autor de ser treinado separado, ou seja, somente esses treinos devem ser exercitados em uma sessão.

Estabelecer a carga nessa periodização o pesquisador se baseou na periodização tática em alguns conteúdos porque a soma das intensidades é constituída o volume, a intensidade que comanda a carga dessa periodização ${ }^{42}$. Embora o artigo não tenha citado nenhuma referência. Porém, a revisão não informou como mensurar essa intensidade durante os tipos de treino, sendo uma limitação.

Nessa periodização a quantificação da carga de treino o volume deve ser mensurado através da quantidade de sessões de cada tipo de treino, dos valores em minutos dedicados a esses tipos de treino e da quantidade de dias treinados e não exercitados. Esse conteúdo é da periodização de cargas seletivas de Gomes ${ }^{1}$, mas isso não foi informado na revisão dessa concepção.

Para estruturar o treino e a carga da sessão da periodização específica para o voleibol o pesquisador se preocupou com as lesões no jogador de voleibol porque a sessão deve ter a duração do jogo ou pouco mais, mas o tempo do treino superior a 3 horas não é indicado por causa do risco de contusão ${ }^{43}$. Outra atenção dessa periodização foi com a quantidade de saltos durante $\mathrm{o}$ treino com bola, merecendo ser programado o volume do treino técnico e do treino em situação de jogo porque um número excessivo de saltos pode levar o voleibolista a lesão ${ }^{24}$. Portanto, aquele estudo inicial sobre a lesão dos fundamentos do voleibol ${ }^{35-37}$ começou a ser utilizado na periodização específica para o voleibol.

Outros conteúdos foram inseridos nessa concepção de periodização. As estações do ano merecem atenção durante a estruturação dessa periodização porque influenciam nos resultados das avaliações cineantropométricas, o treinador também merece conhecer o tempo de evolução e involução das capacidades motoras para estruturar melhor o treino e a sessão recuperativa deve ser prioritariamente com bola, mas também pode ter outro trabalho ${ }^{24}$. A periodização específica para o voleibol não visa o pico do voleibolista porque é mais indicado para esportes individuais, mas a meta é a regularidade competitiva da equipe de voleibol por causa do campeonato duradouro dessa modalidade ${ }^{44}$.

Os microciclos dessa periodização possuem duração de 1 a 20 dias, sendo constituído pelo microciclo forte, médio, fraco, estabilizador, competitivo e de teste e os mesociclos são identificados por uma numeração para o treinador saber a quantidade deles na temporada ${ }^{24}$. Ainda essa concepção possui o período de treino que só ocorre a preparação do atleta, o período competitivo onde acontece a disputa e o período recuperativo que é igual ao período de transição com descanso ativo e/ou passivo.

Entretanto, os microciclos dessa periodização possuem uma limitação, apesar dos seus nomes corresponderem a carga de treino, o autor não informou como é mensurada a carga de cada microciclo. Por exemplo, o treinador prescreve o microciclo forte, não sendo explicado como o técnico e/ou o preparador físico determina que os exercícios correspondem a um treino forte. Então, isso foi uma significativa limitação dessa periodização.

Por último, esse primeiro trabalho teórico sobre a periodização específica para o voleibol foi apresentado o desenho esquemático dessa concepção com diversos conteúdo dessa maneira de estruturar o treino para o voleibol ${ }^{24}$. Porém, esse desenho esquemático é similar ao da periodização tradicional de $\mathrm{Matveev}^{45}$, mas isso não foi mencionado no artigo. A figura 3 mostra esse desenho.

Em 2014, Marques Junior ${ }^{25}$ escreveu um artigo mais embasado sobre a periodização específica para o voleibol. Lembrando, nessa concepção todo o trabalho é específico, servindo apenas para o voleibol. O treino específico visa que os exercícios sejam conforme as necessidades do jogador de voleibol. Verkhoshanski ${ }^{46}$ concluiu: 
"Quanto mais alto for o nível esportivo do atleta, mais válido será o fenômeno de especificidade na sua preparação" (p. 209).

Nesse artigo de revisão o pesquisador fundamentou essa periodização embasado no perfil físico do voleibol (rali e pausa, duração da partida), no desempenho físico dessa modalidade (metragem percorrida em uma jogada) e nas capacidades motoras desse esporte - mais detalhes leia em Arruda e Hespanhol ${ }^{47}$ e em Marques Junior $^{48}$. Outros conteúdos importantes para estruturar essa concepção foram a carga de treino e os esforços dos fundamentos. Também o idealizador da periodização se preocupou com o nível de lesão dos fundamentos. Então, ele nos forneceu um exemplo em como estruturar o treino semanal, sendo o seguinte: foi calculada a carga de treino, onde o tempo de treino corresponde a 120 minutos (min) que equivale a 2 horas de treino, sendo a duração da partida de voleibol. O cálculo da carga de treino é simples ${ }^{18}: 120 \mathrm{~min}=$ $100 \%$, faça uma regra de três e sabendo que o treinador deseja trabalhar na $2^{\mathrm{a}}$ feira com carga de $70 \%$.

O mesmo cálculo foi efetuado para $4^{\mathrm{a}}$ feira (carga de 90\% = $108 \mathrm{~min})$ e para $6^{\mathrm{a}}$ feira (carga de $100 \%=120 \mathrm{~min}$ ). Após esses cálculos, foi distribuído o tempo de treino das atividades, sendo exposto na tabela 1.

Em seguida o segundo artigo sobre a periodização específica para o voleibol determinou os esforços (é a intensidade) dos fundamentos subjetivamente para ser usado como carga de treino da sessão do treino técnico e do treino em situação de jogo ${ }^{25}$. O quadro 1 apresenta esses resultados.

\begin{tabular}{|c|c|c|c|c|c|c|c|c|c|c|}
\hline \multicolumn{11}{|c|}{ Carga } \\
\hline \multicolumn{11}{|c|}{$100 \%$} \\
\hline \multicolumn{11}{|c|}{$90 \%$} \\
\hline \multicolumn{11}{|c|}{ Intusidalt } \\
\hline & & & & & & & & & & \\
\hline & & & & & & & & & & \\
\hline & & & & & & & & & & \\
\hline & & & & & & & & & & \\
\hline \multicolumn{11}{|c|}{$0 \%$} \\
\hline & & & & & & & & & & \\
\hline \multirow{4}{*}{ Prognestico de Methora da Capacidade Fisiea } & Coordenario & & & & & Methon & & & & \\
\hline & Forsa & & & & & Methon & & & & \\
\hline & Pelocidadt & & & & & Methosa & & & & \\
\hline & & & & & & & Flenbilidede & & & Methora \\
\hline Estaçees do Ano & \multicolumn{8}{|c|}{ VER } & \multicolumn{2}{|c|}{ OUTONO } \\
\hline Mierveiclo & Fot & $\mathrm{Fat}$ & $\mathrm{T}$ & E & M & $\mathrm{T}$ & C & $\mathrm{C}$ & $P_{n}$ & $M$ \\
\hline Messuich & \multicolumn{3}{|c|}{1} & \multicolumn{3}{|c|}{2} & \multicolumn{2}{|c|}{3} & \multicolumn{2}{|r|}{4} \\
\hline Mleses & \multicolumn{3}{|c|}{ Intivo } & \multirow{2}{*}{\multicolumn{3}{|c|}{ Fevertito }} & \multicolumn{2}{|c|}{ Marso } & \multicolumn{2}{|c|}{ Abrl } \\
\hline Peniodo & \multicolumn{3}{|c|}{ de Treno } & & & & \multicolumn{2}{|c|}{ Competitivo } & \multicolumn{2}{|c|}{ Retupentitvo } \\
\hline
\end{tabular}

Figura 3. Primeiro desenho esquemático da periodização específica para o voleibol (Ilustração elaborada pelo autor).

\section{Carga de Treino de $2^{a}$ feira}

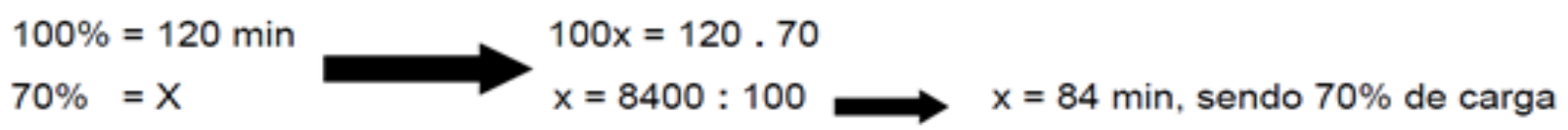


Tabela 1. Magnitude da carga em minutos.

\begin{tabular}{cccc}
\hline Treino & $\mathbf{2}^{\mathbf{a}}$ feira & $\mathbf{4}^{\mathbf{a}} \mathbf{f}$ & $\mathbf{6}^{\mathbf{a}} \mathbf{f}$ \\
\hline Técnico & $10 \mathrm{~min}$ & $5 \mathrm{~min}$ & $5 \mathrm{~min}$ \\
\hline Situacional & $10 \mathrm{~min}$ & $25 \mathrm{~min}$ & $30 \mathrm{~min}$ \\
\hline de Jogo & $15 \mathrm{~min}$ & $30 \mathrm{~min}$ & $30 \mathrm{~min}$ \\
\hline Musculação & $49 \mathrm{~min}$ & $48 \mathrm{~min}$ & $55 \mathrm{~min}$ \\
\hline Total & $\mathbf{8 4} \mathbf{~ m i n}$ & $\mathbf{1 0 8} \mathbf{~ m i n}$ & $\mathbf{1 2 0} \mathbf{~ m i n}$ \\
\hline
\end{tabular}

\section{Quadro 1. Esforços dos fundamentos.}

\begin{tabular}{|l|c|}
\hline \multicolumn{1}{|c|}{ Esforço Subjetivo } & Fundamentos \\
\hline Máximo & $\begin{array}{c}\text {. Salto (saque, levantamento, bloqueio e ataque) } \\
\text {. Mergulhos (peixinho e rolamento) }\end{array}$ \\
Médio ou Baixo & $\begin{array}{c}\text {. Corrida de alta velocidade para chegar na bola (ocorre na defesa) } \\
\text {. Passagem da posição de expectativa para a defesa de manchete ou de } \\
\text { toque } \\
\text {. Saque tipo tênis e outros fundamentos com os pés no solo } \\
\text {. Recepção } \\
\text {. Levantamento sem salto }\end{array}$ \\
\hline Baixo & . Posição de expectativa antes de efetuar a recepção \\
\hline
\end{tabular}

Outro conteúdo utilizado para estruturar a carga de treino é o nível de lesão dos fundamentos do voleibol, sendo exposto na tabela 2.

O artigo de 2014 também estabeleceu a carga de treino em percentual, sendo útil para classificar o valor do volume (é o tempo de treino, ver regra de três) e da intensidade (é o esforço subjetivo dos fundamentos) - ver tabela 3 . Baseado na tabela 1 da carga em minutos e a escolha dos fundamentos trabalhados tendo como parâmetro $\quad \mathrm{o}$ quadro 1 dos esforços dos fundamentos, é possível determinar o percentual (\%) do volume e da intensidade. Também foi usada a tabela 2 e 3 . Então veja esse resultado na tabela 4.

Tabela 2. Nível de lesão dos fundamentos.

\begin{tabular}{cc}
\hline Nível de Lesão & Fundamentos \\
\hline $1^{\circ}$ lugar & Salto (saque, levantamento, bloqueio e ataque) \\
$2^{\circ}$ lugar & Ações defensivas (mergulhos, sprint para fazer a defesa) \\
$3^{\circ}$ lugar & Golpe na bola (saque e ataque) \\
$4^{\circ}$ lugar & Ações das mãos (principalmente no bloqueio) \\
$5^{\circ}$ lugar & Recepção e Levantamento sem salto \\
\hline
\end{tabular}

Tabela 3. Carga de treino. 


\begin{tabular}{ccc}
$\begin{array}{c}\text { Classificação da Carga de } \\
\text { Treino }\end{array}$ & Percentual da Carga & Objetivo \\
\hline Baixa & 15 a $25 \%$ & Recuperação do atleta \\
Média & 40 a $60 \%$ & Manutenção do nível de treino \\
\hline Alta & 65 a $75 \%$ & Estabilização ou aumento do nível \\
Máxima & 80 a $100 \%$ & Aumento do do nível de treino \\
\hline
\end{tabular}

A carga de treino do trabalho com bola nesse segundo artigo da periodização específica para o voleibol é constituído pelo tempo do jogo em minutos, os esforços dos fundamentos subjetivamente e o nível de lesão dos fundamentos. Porém, o pesquisador da periodização específica para o voleibol acrescentou outros conteúdos na carga de treino (quantidade de fundamentos, intensidade subjetiva da prática da aprendizagem motora e outros) e isso prejudicou o treinador em mensurar a carga. Esse ocorrido foi uma limitação desse segundo trabalho sobre essa periodização. Enquanto que a carga de treino do treino físico está inserido a duração do jogo em minutos e com o uso de cálculos matemáticos foi ensinado como estabelecer a carga da musculação, do treino intervalado e outros. Mais detalhes veja em Marques Junior $^{25}$.

Outro conteúdo importante do segundo artigo da periodização específica para o voleibol foi apresentado para o leitor as atividades de treino para o voleibolista (treino com bola e treino físico como a musculação, o treino de força reativa e outros). Nesse artigo o desenho esquemático foi melhorado em relação ao anterior, sendo exposto os conteúdos do treino e a carga é representada por uma linha azul tracejada com uma bola. Esse desenho foi criado baseado na periodização de Matveev e na periodização do esquema estrutural de cargas de alta intensidade de Tschiene $^{28}-$ ver figura 4.

1.3. Período da elaboração das escalas de percepção subjetiva e da estruturação da carga de treino - 2016 e 2017
Em 2012 o idealizador da periodização específica para o voleibol iniciou os estudos como aluno especial (Aluno especial é um estudante que está conhecendo a linha de pesquisa do doutorado ou do mestrado e cursa uma disciplina desse stricto sensu com o intuito de obter um contato mais próximo com o orientador e com o conteúdo da linha de pesquisa na área de concentração Atividade e Desempenho Humano) no doutorado da Universidade Gama Filho em Ciências do Exercício e do Esporte. A sua intenção de pesquisa era a escala de prescrição da intensidade subjetiva do esforço do treino, tendo seu nome abreviado como escala de PISE treino $^{49}$. Porém, em 2014 essa instituição faliu e a intenção de doutorado foi cancelada.

Entretanto, como esse aluno fez uma extensa coleta de dados sobre a escala de percepção subjetiva do esforço (PSE) e escreveu alguns artigos sobre esse tema ${ }^{50-52}$, ele resolveu elaborar a escala de dor muscular ${ }^{53-55}$ e a escala de PSE adaptada de Foster ${ }^{56}$. Portanto, a escala de dor muscular estabelece o nível de fadiga do atleta indiretamente ${ }^{57}$ e a escala de PSE adaptada de Foster determina a intensidade da tarefa e por cálculos matemáticos o treinador determina a carga de treino ${ }^{56}$.

A partir de 2017 a periodização específica para o voleibol passou utilizar essas duas escalas no seu treinamento. $\mathrm{O}$ artigo sobre carga de treino de Marques Junior ${ }^{26}$, utilizou o método de Foster $^{58}$ para estabelecer a carga da sessão (duração em minutos do treino x classificação da escala PSE $=$ ? Unidades arbitrárias). Enquanto que o segundo artigo sobre esse tema explicou os microciclos dessa periodização e como usar o macrociclo elaborado no Excel $_{\circledast}{ }^{27}$. 
Tabela 4. Organização do treino com bola.

\begin{tabular}{|c|c|c|c|c|}
\hline $\mathbf{S}$ & Tipo de Treino & Atividade & Volume e Intensidade & PLF \\
\hline & $\begin{array}{l}\text { Técnico (10 min, carga de } \\
12 \%) \\
\text { Treino técnico determinado } \\
\text { pela regra de três: } \\
\mathbf{1 0 0 \%}=\mathbf{1 2 0} \mathbf{m i n} \\
\mathbf{1 0 \%}=\mathbf{x} \\
100 x=120.10 \\
\text { x }=1200: 100=12 \% \\
\text { Situacional }(10 \text { min, } 12 \%) \\
\text { de Jogo }(15 \text { min, } 18 \%) \\
\text { Musculação }(49 \text { min, } 58 \%) \\
\text { Tempo Total = } \mathbf{8 4} \text { min (carga } \\
\text { de } 70 \% \text { é alta, ver na regra de } \\
\text { três do texto) }\end{array}$ & $\begin{array}{l}\text { Toque (carga de 25\%) } \\
\text { Saque com salto }(90 \%) \text {, } \\
\text { recepção }(60 \%) \\
\text { levantamento com salto } \\
(80 \%) \text { - média }=(90+60 \\
+80): 3=76,6 \% \text {. } \\
\text { Partida (titular versus } \\
\text { reserva) - não dá para } \\
\text { mensurar a carga. } \\
\text { Membro superior, membro } \\
\text { inferior e tronco }\end{array}$ & $\begin{array}{c}\text { Volume }=12 \% \\
\text { Intensidade }=25 \% \\
\text { Volume }=12 \% \\
\text { Intensidade }=76,6 \% \\
\text { Volume }=18 \% \\
\text { Intensidade = não dá para } \\
\text { mensurar } \\
\text { Volume }=58 \% \\
\text { Intensidade }=- \\
\text { Média } \\
\text { Volume = 25\% (baixa) } \\
\text { Intensidade = 50,8\% } \\
\text { (média) }\end{array}$ & 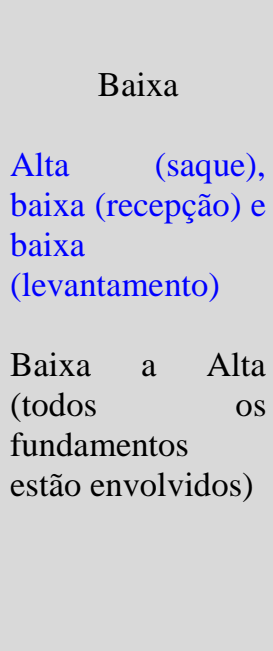 \\
\hline $3^{\mathbf{a}} \mathbf{f}$ & Descanso & & & \\
\hline $4^{\mathrm{a}} \mathrm{f}$ & $\begin{array}{l}\text { Musculação (48 min, 57\%) } \\
\text { Tempo Total = } 108 \text { min }(90 \% \\
\text { é máxima) }\end{array}$ & $\begin{array}{l}\text { Saque com salto }(90 \%) \text {, } \\
\text { recepção }(60 \%) \\
\text { levantamento com salto } \\
(80 \%) \text { e ataque }(95 \%)- \\
\text { média }=(90+60+80+ \\
95): 4=81,25 \% \text {. } \\
\text { Partida (titular versus } \\
\text { reserva) - não dá para } \\
\text { mensurar a carga. } \\
\text { Membro superior, membro } \\
\text { inferior e tronco }\end{array}$ & $\begin{array}{c}\text { Volume }=6 \% \\
\text { Intensidade }=25 \% \\
\text { Volume }=30 \% \\
\text { Intensidade }=81,25 \% \\
\text { Volume }=36 \% \\
\text { Intensidade }=\text { não dá para } \\
\text { mensurar } \\
\text { Volume }=57 \% \\
\text { Intensidade }=- \\
\text { Média } \\
\text { Volume }=32,25 \% \text { (baixa) } \\
\text { Intensidade }=53,12 \% \\
\text { (média) }\end{array}$ & $\begin{array}{l}\text { Alta (saque), } \\
\text { baixa (recepção) e } \\
\text { baixa } \\
\text { (levantamento) } \\
\text { alta (ataque) } \\
\text { Baixa a Alta } \\
\text { (todos os } \\
\text { fundamentos } \\
\text { estão envolvidos) }\end{array}$ \\
\hline $5^{\mathrm{a}} \mathrm{f}$ & Descanso & & & \\
\hline $6^{\mathrm{a}} \mathrm{f}$ & $\begin{array}{l}\text { Técnico (5 min, 6\%) } \\
\text { Situacional (30 min, 36\%) }\end{array}$ & $\begin{array}{l}\text { Recepção (25\%) } \\
\text { Ataque e Bloqueio (100\%) } \\
\text { Partida (titular versus } \\
\text { reserva) - não dá para } \\
\text { mensurar a carga. } \\
\text { Membro superior, membro } \\
\text { inferior e tronco }\end{array}$ & $\begin{array}{c}\text { Volume }=6 \% \\
\text { Intensidade }=25 \% \\
\text { Volume }=36 \% \\
\text { Intensidade }=100 \% \\
\text { Volume }=36 \% \\
\text { Intensidade }=\text { não dá para } \\
\text { mensurar } \\
\text { Volume }=66 \% \\
\text { Intensidade }=- \\
\text { Média } \\
\text { Volume }=36 \%(\text { baixa) } \\
\text { Intensidade }=62,5 \% \\
\text { (média) }\end{array}$ & $\begin{array}{l}\text { Baixa } \\
\text { Alta (ataque e } \\
\text { bloqueio) } \\
\text { Baixa a Alta } \\
\text { (todos a os } \\
\text { fundamentos } \\
\text { estão envolvidos) }\end{array}$ \\
\hline
\end{tabular}

Observação (Obs.): Em atividade a carga foi estabelecida subjetivamente, baseado no quadro 1, na tabela 2 e 3, PLF: Probabilidade de Lesão nos Fundamentos, S: Semana. 


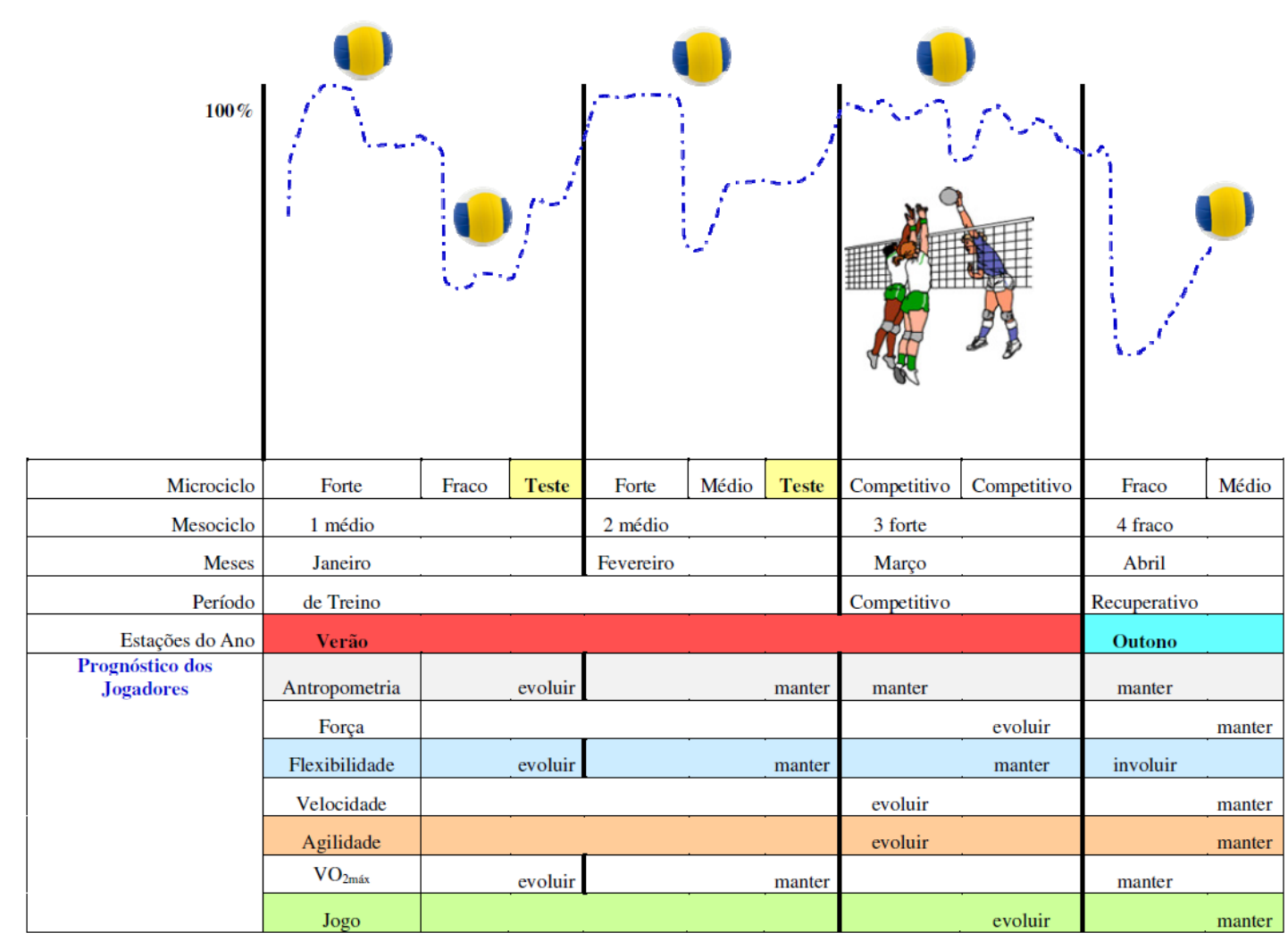

Figura 4. Segundo desenho esquemático da periodização específica para o voleibol (Ilustração elaborada pelo autor).

\subsection{Período da estruturação do treino - 2018 a 2020}

Em 2018 foi escrito o $1^{\circ}$ artigo em inglês sobre a periodização específica para o voleibol, sendo uma mini revisão ${ }^{28}$. Nesse trabalho o autor apresentou uma visão geral sobre essa concepção, mas não abordou sobre o nível de lesão que faz parte da carga de treino. Porém, nesse artigo o pesquisador apresentou os conteúdos de outros tipos de periodização que foram utilizados para estruturar a periodização específica para o voleibol e os conteúdos da Educação Física que foram aplicados para criar essa concepção de periodização. A mini revisão explicou como os esforços dos fundamentos pela frequência cardíaca (FC) são úteis para o treinador elaborar o treino técnico e o treino em situação de jogo.

O $2^{\circ}$ artigo em inglês sobre periodização específica para o voleibol forneceu o conteúdo completo sobre essa concepção ${ }^{29}$. Nessa revisão o autor apresentou os três conteúdos interconectados (sequência definida dos fundamentos do voleibol, esforços dos fundamentos do voleibol e nível de lesão dos fundamentos do voleibol) que são utilizados nos três tipos de treino com bola (treino técnico, treino em situação de jogo e treino de jogo). Esses conteúdos interconectados são úteis para o treinador estruturar o treino com bola $\mathrm{e}$ estabelecer a carga subjetivamente antes e durante a sessão. Isso só ocorre no treino técnico e no treino em situação de jogo.

Porém, no treino de jogo acontece apenas a sequência definida dos fundamentos e não é possível controlar subjetivamente a carga da sessão antes e durante o treino ${ }^{59}$. Lembrando, ao mesmo tempo que o técnico controla subjetivamente a carga de treino pelo esforço dos fundamentos e pelo nível de lesão, todo trabalho ocorre conforme o objetivo da sessão. A figura 5 apresenta os conteúdos interconectados que são utilizados em cada tipo de treino com controle subjetivo da carga de treino. 

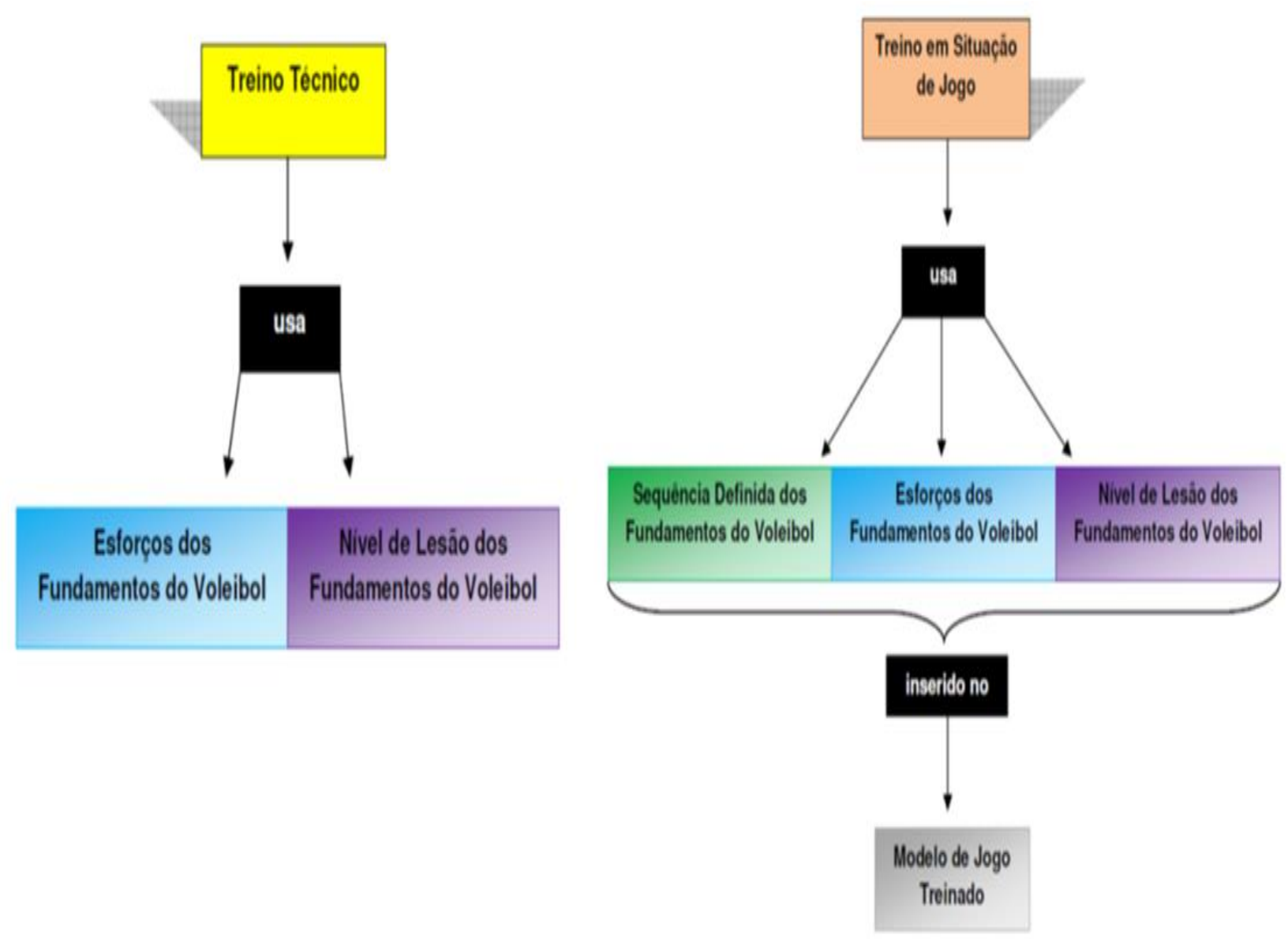

Figura 5. Conteúdo interconectado de cada tipo de treino (Ilustração elaborada pelo autor).

Também nessa revisão o autor forneceu uma importante tabela para o treinador estruturar o treino técnico e em situação de jogo. A classificação do percentual de lesão dessa tabela foi estabelecida pelo autor, sendo a seguinte: 0 a 10 é baixa, 11 a 21 é média e 22 ou mais é alta. O leitor pode ver essa tabela a seguir.

Continuando a análise do mesmo artigo de Marques Junior ${ }^{29}$, o pesquisador informou como organizar o treino físico. A ênfase nessa concepção é o treino de força, com prioridade na força rápida de resistência na musculação e no treino de força reativa, mais conhecido como treino pliométrico. $\mathrm{O}$ treinamento físico pode ocorrer integrado com o treino com bola ou somente com essa tarefa, mas é indicado do treino físico ser realizado com o treino intermitente de máxima intensidade de Cometti ${ }^{39}$.
Continuando a explicar os conteúdos do treino com bola, Marques Junior ${ }^{33}$ escreveu uma revisão explicando em como estruturar subjetivamente a carga do treino técnico e do treino em situação de jogo antes da sessão. Entretanto, um conteúdo foi aperfeiçoado, para elaborar o treino com bola o treinador deveria consultar a tabela 5, mas essa tabela foi substituída pelo gráfico da classificação do treino com bola.

O gráfico da classificação do treino com bola conforme o fundamento (baixo, médio e alto) facilita o treinador de estruturar e prescrever a carga de treino subjetivamente antes dos atletas efetuarem o treinamento de cada exercício do treino técnico e do treino em situação de jogo e estando conforme o objetivo da sessão. Esse gráfico foi baseado no esforço dos fundamentos e no nível de lesão dos fundamentos. A figura 6 apresenta esse gráfico.

Tabela 5. Valores para prescrever o treino. 


\begin{tabular}{|c|c|c|c|}
\hline Fundamento & Esforço (FC) & $\begin{array}{l}\text { Percentual de } \\
\text { Lesão }\end{array}$ & Resultado para Estruturar o Treino \\
\hline $\begin{array}{l}\text { Saque Tênis } \\
\text { Recepção }\end{array}$ & $\begin{array}{c}\text { Leve (104 a } 130 \text { bpm) } \\
\text { Leve a Médio (131 a } 150 \\
\text { bpm) }\end{array}$ & $\begin{array}{c}8 \text { a } 20 \% \text { (baixa a } \\
\text { média) } \\
1 \text { a } 14 \% \text { (baixa) }\end{array}$ & $\begin{array}{l}\text { Esforço leve e Nível de lesão baixa a } \\
\text { média } \\
\text { Esforço leve a médio e Nível de lesão } \\
\text { baixa }\end{array}$ \\
\hline $\begin{array}{c}\text { Levantamento } \\
\text { Defesa }\end{array}$ & $\begin{array}{l}\text { Leve a Médio (120 a } 155 \\
\qquad \text { bpm) } \\
\text { Leve a Médio (126 a } 160 \\
\text { bpm) }\end{array}$ & $\begin{array}{l}2 \text { a } 37 \% \text { (baixa a } \\
\text { alta) } \\
5 \text { a } 37 \% \text { (baixa a } \\
\text { alta) }\end{array}$ & $\begin{array}{l}\text { Esforço leve a médio e Nível de lesão } \\
\text { baixa a alta } \\
\text { Esforço leve a médio e Nível de lesão } \\
\text { baixa a alta }\end{array}$ \\
\hline $\begin{array}{c}\text { Saque com } \\
\text { Salto } \\
\text { Ataque } \\
\text { Levantamen } \\
\text { to com Salto } \\
\text { Bloqueio } \\
\text { Corrida de } \\
\text { Velocidade }\end{array}$ & $\begin{array}{c}\text { Médio a Forte } \\
\text { (150 a } 190 \text { bpm) } \\
\text { Médio a Forte } \\
\text { (150 a } 190 \text { bpm) } \\
\text { Médio a Forte } \\
\text { (155 a } 200 \text { bpm) } \\
\text { Médio a Forte } \\
\text { (169 a } 198 \text { bpm) } \\
\text { Médio a Forte } \\
\text { (168 a } 200 \text { bpm) }\end{array}$ & $\begin{array}{r}8 \text { a } 32 \% \\
\text { (baixa a alta) } \\
8 \text { a } 32 \% \\
\text { (baixa a alta) } \\
2 \text { a } 37 \% \\
\text { (baixa a alta) } \\
8 \text { a } 41 \% \\
\text { (baixa a alta) } \\
8 \text { a } 37 \% \\
\text { (baixa a alta) }\end{array}$ & $\begin{array}{l}\text { Esforço médio a forte e Nível } \\
\text { de lesão baixa a alta } \\
\text { Esforço médio a forte e Nível } \\
\text { de lesão baixa a alta } \\
\text { Esforço médio a forte e Nível } \\
\text { de lesão baixa a alta } \\
\text { Esforço médio a forte e Nível } \\
\text { de lesão baixa a alta } \\
\text { Esforço médio a forte e Nível } \\
\text { de lesão baixa a alta }\end{array}$ \\
\hline
\end{tabular}

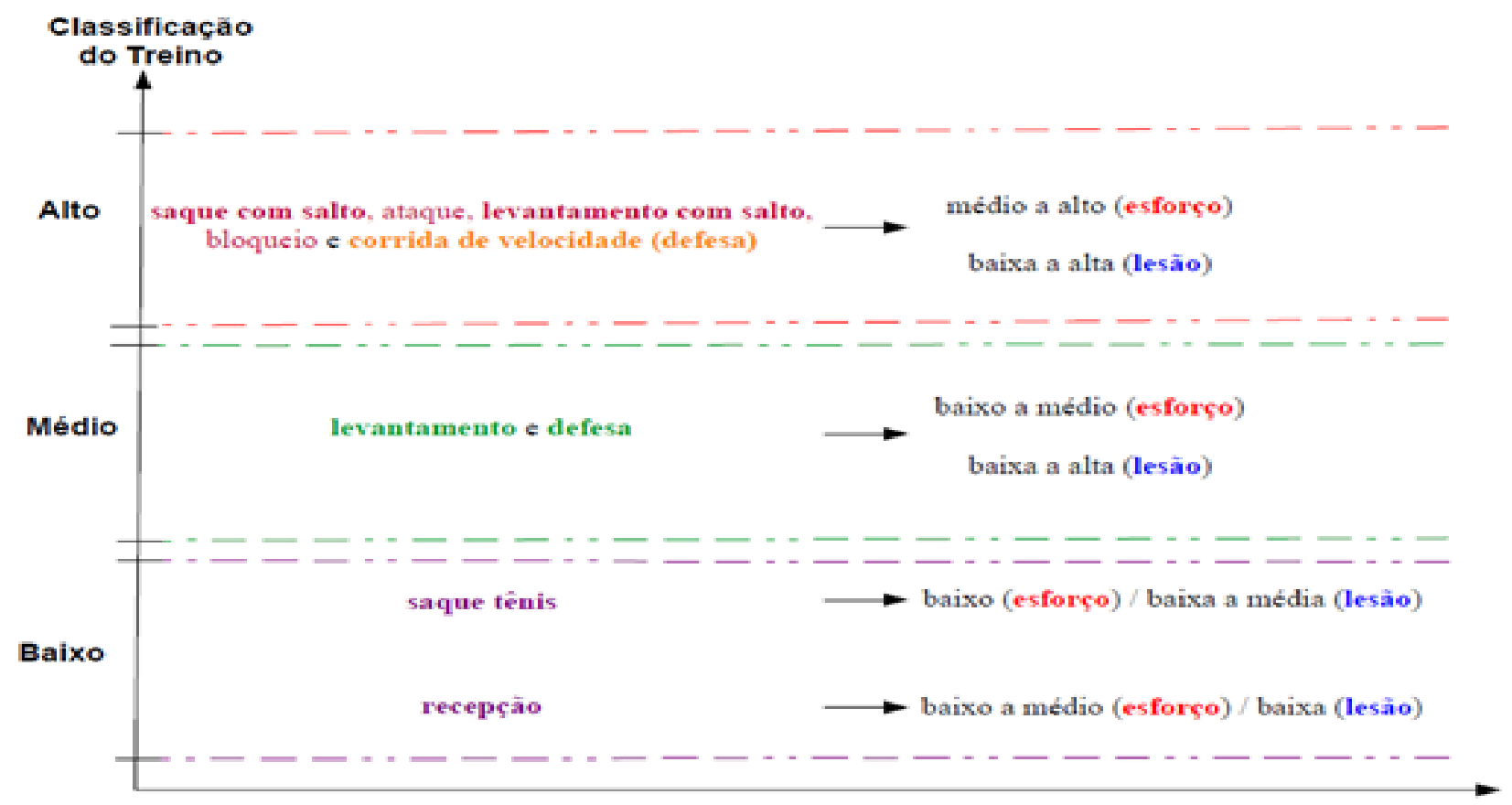

Figura 6. Gráfico da classificação do treino com bola conforme o fundamento (Ilustração elaborada pelo autor). 
Após a sessão do treino com bola é estabelecida a carga de treino pela escala adaptada de Foster $^{56}$ e a fadiga pela escala de dor muscular ${ }^{55}$. Entretanto, o jogo não é possível de detectar subjetivamente a carga da sessão antes do treino.

O último artigo publicado de Marques Junior $^{30}$ foi a continuação dos dois últimos trabalhos ${ }^{29,33}$. Nesse artigo foi explicado todo o conteúdo da periodização específica para o voleibol, sendo um aperfeiçoamento dos trabalhos anteriores desse autor. $\mathrm{O}$ gráfico da classificação do treino com bola conforme o fundamento foi melhorado do último estudo de Marques Junior ${ }^{33}$, veja na figura 7.

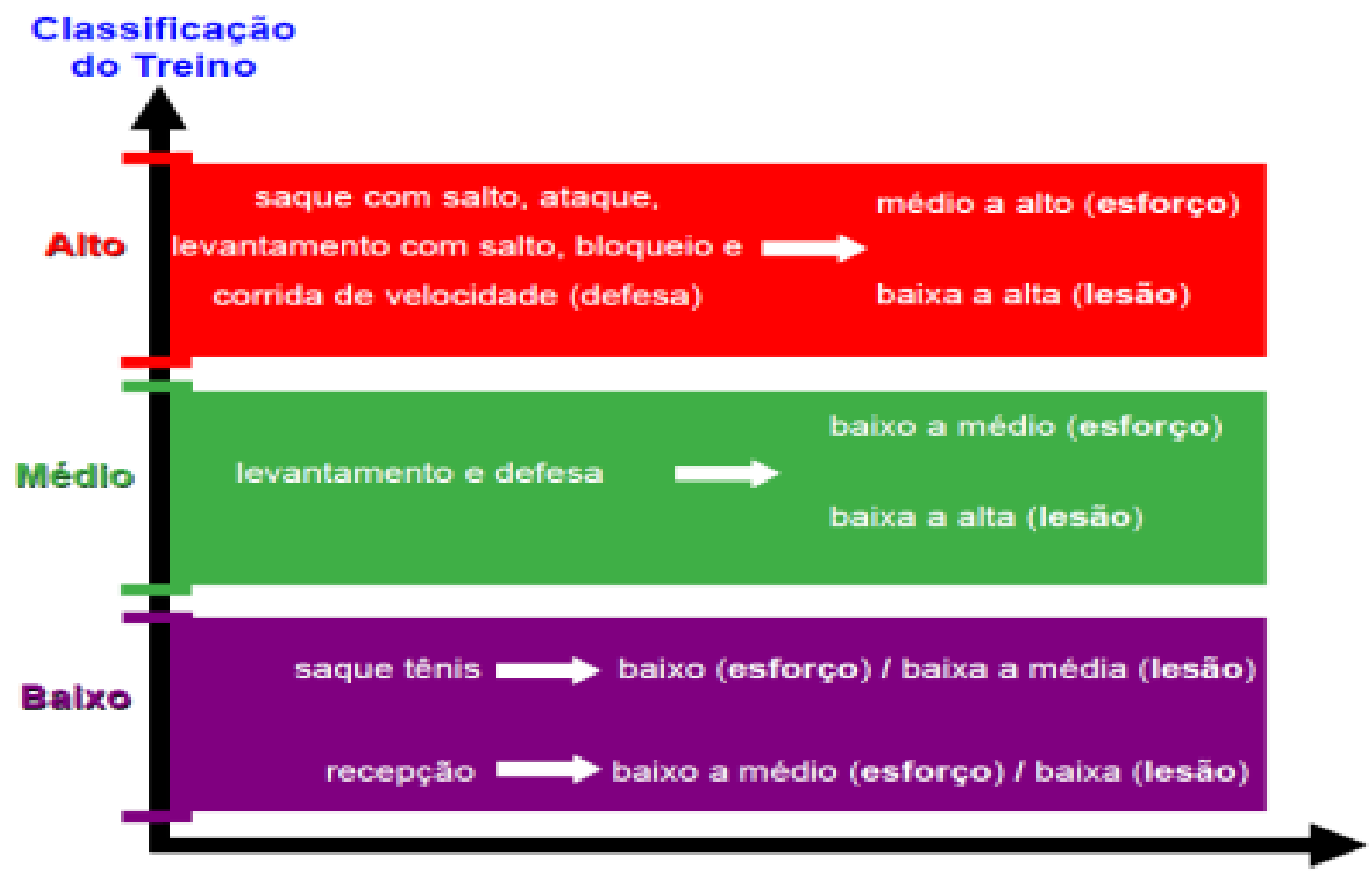

Figura 7. Gráfico da classificação do treino com bola para o técnico elaborar o treino técnico e o treino em situação de jogo (Ilustração elaborada pelo autor).

O autor também apresentou as capacidades motoras condicionantes (força, velocidade, resistência e flexibilidade) que merecem ser treinadas e informou que a força é a capacidade motora condicionante mais importante para o voleibol, devendo ser exercitada através da força rápida resistência e pela força reativa ${ }^{30}$.

Um conteúdo importante que foi explicado nesse artigo foi o tempo de evolução da capacidade motora e o efeito residual do treino da capacidade motora. Esses conteúdos são importantes para nortear o treinamento e são expostos na tabela.

$\mathrm{O}$ efeito residual do treino foi retirado da periodização em bloco ATR de Issurin e Kaverin ${ }^{60}$. Em conclusão, a teoria da periodização específica para o voleibol vem sendo melhorada ao longo dos anos com o objetivo de resolver os problemas do jogador de voleibol. A figura 8 apresenta as periodizações e disciplinas da educação física que estruturaram essa concepção de periodização.

\subsection{Período das ideias dos estudos científicos - 2019}

Em 2019, Marques Junior ${ }^{31}$ escreveu uma revisão com todos os conteúdos da periodização específica para o voleibol e sugeriu diversos experimentos para essa concepção deixar de ser uma teoria. Portanto, o autor escreveu os estudos que merecem ser conduzidos nessa periodização para essa concepção se tornar uma adequada periodização.

$\mathrm{O}$ estudante que leu esse artigo de Marques Junior $^{31}$ observou a linha do tempo em 2019 dois artigos da Revista Con-Ciencias del Deporte, esses dois trabalhos foram excluídos a pedido do autor porque parte do conteúdo foi publicado nessa revisão que você acabou de ler. 
Tabela 6. Conteúdo para organizar o treino.

\begin{tabular}{|c|c|c|c|}
\hline $\begin{array}{l}\text { Capacidade } \\
\text { Motora }\end{array}$ & Treino & Tempo de Evolução & $\begin{array}{c}\text { Efeito Residual do } \\
\text { Treino }\end{array}$ \\
\hline força máxima & musculação & 4 a 5 meses & $\begin{array}{l}30 \pm 5 \text { dias (alto efeito } \\
\text { residual do treino) }\end{array}$ \\
\hline aeróbio & $\begin{array}{c}\text { cíclico (corrida, natação e } \\
\text { outros) }\end{array}$ & 15 dias a 2 meses & $30 \pm 5$ dias (alto) \\
\hline $\begin{array}{l}\text { força rápida de } \\
\text { resistência }\end{array}$ & musculação & 4 a 5 meses & $15 \pm 5$ dias (médio) \\
\hline anaeróbio láctico & $\begin{array}{c}\text { cíclico (corrida, natação e } \\
\text { outros) }\end{array}$ & 1 mês e 14 dias a 3 meses & 18 \pm 4 dias (médio) \\
\hline força rápida & musculação & 4 a 5 meses & $5 \pm 3$ dias (baixo) \\
\hline força reativa & $\begin{array}{c}\text { pliométrico (membro } \\
\text { inferior) }\end{array}$ & 2 a 6 meses (salto vertical) & $5 \pm 3$ dias (baixo) \\
\hline anaeróbio aláctico & $\begin{array}{c}\text { cíclico (corrida, natação e } \\
\text { outros) }\end{array}$ & 1 mês e 14 dias a 3 meses & $5 \pm 3$ dias (baixo) \\
\hline flexibilidade & alongamento & 2 a 3 meses & não informou \\
\hline técnica e tática & bola & 9 dias a 1 mês & não informou \\
\hline
\end{tabular}

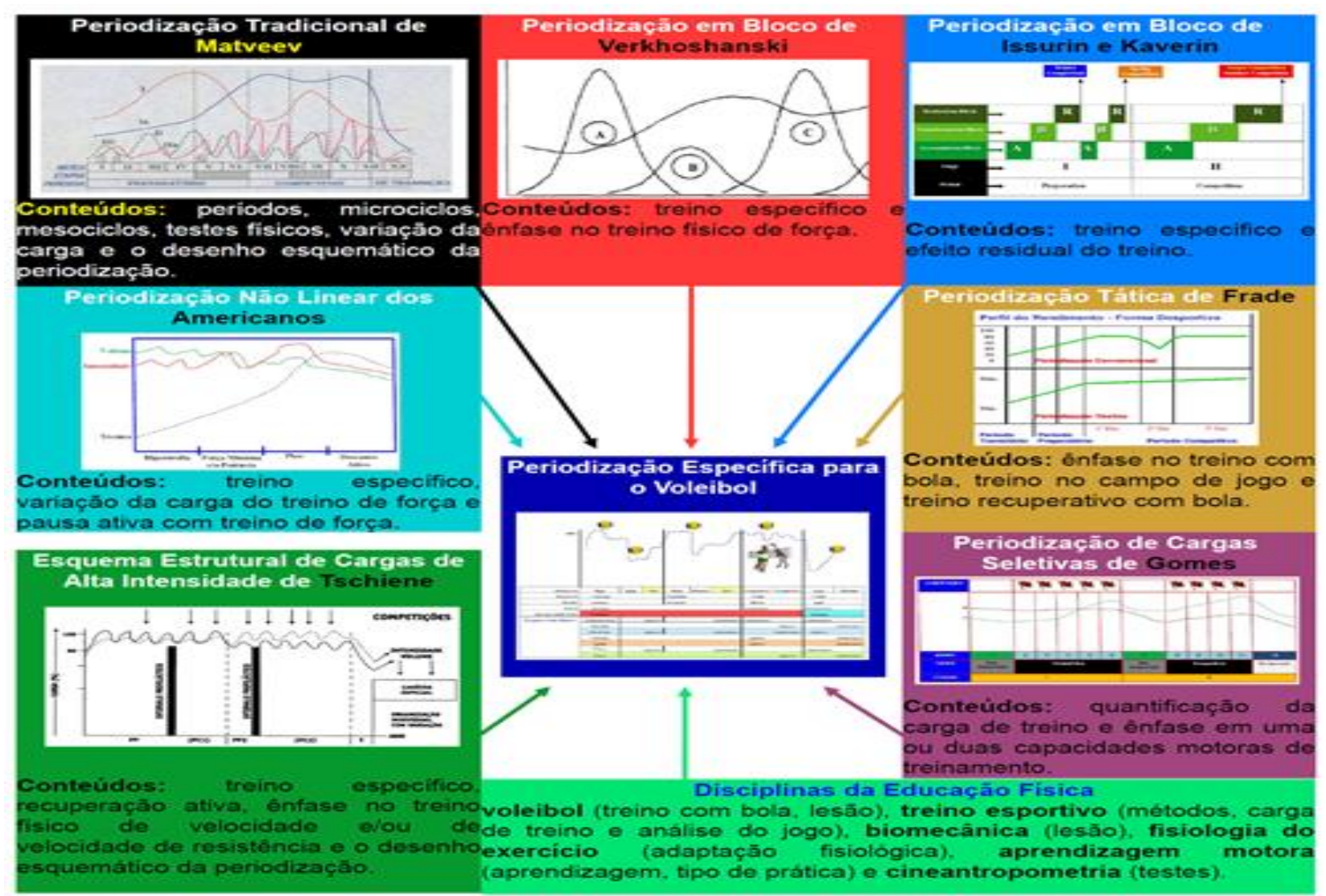

Figura 11. Concepções e disciplinas da educação física que criaram a periodização específica para o voleibol (Ilustração elaborada pelo autor). 


\section{Conclusões}

A história da periodização é dividida em três períodos (empírico, científico e contemporâneo) e cada concepção de periodização possui uma característica que está relacionada com o período que ele pertence. Mas na história da periodização específica para o voleibol é constituído por cinco períodos que foram úteis para fundamentar cientificamente a teoria dessa concepção. Ao todo foram conduzidos 9 artigos de revisão para construir a teoria dessa periodização nos anos de 2011 a $2020^{24-31,33}$. Porém, ainda é necessário acontecer o período dos estudos científicos para os pesquisadores detectarem os acertos e falhas dessa concepção de periodização. Embora já tenha sido conduzido duas pesquisas com essa periodização, mas foi realizado em dois estudos de caso ${ }^{23,61}$. Sendo necessário de pesquisas em equipes e duplas do voleibol em uma temporada para verificar os benefícios dessa concepção para os jogadores e de detectar as limitações dessa periodização, onde o idealizador precisa melhorar o conteúdo dessa periodização. Em conclusão, a história da teoria da periodização específica para o voleibol é um importante estudo para o treinador compreender a evolução das pesquisas dessa concepção.

\section{Referências}

1. Gomes A. Treinamento esportivo: estruturação e periodização. $2^{\mathrm{a}}$ ed. Porto Alegre: Armed.

2. Manso J, Valdivielso M, Caballero J. Planificación del entrenamiento deportivo. Madrid: Gymnos; 1996.

3. Costa I. Los modelos de planificación del entrenamiento deportivo del siglo XX. Rev Electr Ci Apl Dep 2013;6(22):1-9.

4. Marques Junior N. Periodization models used in the current sport. MOJ Sports Med 2020;4(1):27-34.

5. Rigolin da Silva L. Treinamento esportivo: diferenciação entre adultos e crianças e adolescentes. In. Rigolin da Silva L, editor. Desempenho esportivo: treinamento com crianças e adolescentes. São Paulo: Phorte; 2006. p. 13-53.

6. Marques Junior N. Breve história sobre a evolução da periodização esportiva. Rev Edu Fís com Ci Apl Dep 2020;12(25):33-50.

7. Garganta J. Programação e periodização do treino em futebol: das generalidades à especificidade. In. Bento J, Marques A., editores. A ciência do desporto a cultura e o homem. Porto: Universidade do Porto. 1993. p. 259-270.

8. Monge da Silva M. Horizonte com Monge da Silva. Rev Horiz 1988;4(11):183-186.

9. Bizzocchi C. Bizzocchi C. Planejamento em esportes coletivos. In. Rose Junior D, organizador. Modalidades esportivas coletivas. Rio de Janeiro: Guanabara; 2006. p. 90-112.

10. Marques Junior N, Arruda D, Api H. Periodização tradicional no voleibol (parte 1). Rev Con Ci Dep 2019;1(2):31-55.

11. Grigoletto M, Puerto J, Montaner B, Jiménez J, Prada R, Melero C, Vaamonde D, Ugrinowitsch C, Manso J. Efecto de un mesociclo de fuerza máxima sobre la fuerza, potencia y capacidad de salto en un equipo de voleibol de superliga. Rev Andal Med Dep 2008;1(2):51-56.

12. Oliveira P. Periodização contemporânea do treinamento desportivo. São Paulo: Phorte; 2008.

13. Simões R, Salles G, Gonelli P, Leite G, Dias R, Cavaglieri C, Pellegrinotti I, Borin J, Verlengia R, Alves S, Cesar M. Efeitos do treinamento neuromuscular na aptidão cardiorrespiratória e composição corporal de atletas de voleibol do sexo feminino. Rev Bras Med Esp 2009;15(4):295-298. 
14. Altini Neto A, Pellegrinotti I, Montebelo M. Efeitos de um programa de treinamento neuromuscular sobre o consumo máximo de oxigênio e o salto vertical em atletas iniciantes de voleibol. Rev Bras Med Esp 2006;12(1):33-38.

15. Marques Junior N. Voleibol: biomecânica e musculação aplicadas. Rio de Janeiro: GPS; 2001.

16. Marques Junior N. Preparação de força especial para o voleibolista. Lecturas Educ Fís Dep 2004;10(70):1-6.

17. Marques Junior N. Uma preparação desportiva para o voleibol: periodização, avaliação funcional e condicionamento físico. Rev Min Educ Fís 2002;10(2):49-73.

18. Marques Junior N. Sugestão de uma periodização para o voleibol "amador" de duplas na areia masculina. [Monografia de Especialização]. Rio de Janeiro: UGF; 2005

19. Marques Junior N. Periodização tática: uma nova organização do treinamento para duplas masculinas do voleibol na areia de alto rendimento. Rev Min Educ Fís 2006;14(1):19-45.

20. Marques Junior N. O efeito da periodização em um atleta do voleibol na areia 1999 a 2008. Mov Percep 2009;10(15):54-94.

21. Marques Junior N. A continuação do estudo sobre o efeito da periodização em um jogador do voleibol na areia, 2009 a 2012. Lecturas Educ Fís Dep 2013;17(178):132.

22. Marques Junior N. Estudo de um jogador do voleibol na areia: verificação do preparo físico e a identificação do fluxo sanguíneo cerebral, 1999 a 2013. Rev Bras Prescr Fisio Exerc 2015;9(55):462-474.

23. Marques Junior N. Estimativa da gordura corporal de um jogador de voleibol, 1999 a 2018. Olimpia 2019;16(53):12-22.

24. Marques Junior N. Modelos de periodização para os esportes. Rev Bras Prescr Fisio Exerc 2011;5(26):143-162.

25. Marques Junior N. Periodização específica para o voleibol: atualizando o conteúdo. Rev Bras Prescr Fisio Exerc 2014;8(47):453-484.

26. Marques Junior N. Periodização específica para o voleibol: atualizando o conteúdo da carga de treino. Rev Observatorio Dep 2017;3(4):32-60.

27. Marques Junior N. Periodização específica para o voleibol: uso do macrociclo

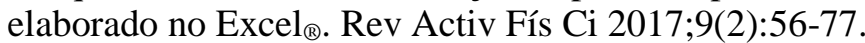

28. Marques Junior N. Specific periodization for the volleyball: a training organization. MOJ Sports Med 2018;2(3):108-111.

29. Marques Junior N. Specific periodization for the volleyball: a training organization with ball and of the physical training. Rev Bras Prescr Fisio Exerc 2019;13(81):58 69.

30. Marques Junior N. Specific periodization for the volleyball: the importance of the residual training effects. MOJ Sports Med 2020;4(1):4-11.

31. Marques Junior N. Periodização específica para o voleibol: uma teoria que merece pesquisa. Olimpia, 16(57), 150-160.

32. Melo V. História da educação física e do esporte no Brasil. $3^{\mathrm{a}}$ ed. São Paulo: Ibrasa; 2006.

33. Marques Junior N. Periodização específica para o voleibol: estruturação subjetiva da carga do treino com bola. Rev Peruana Ci Activ Fís Dep 2021;-(-), -. Avaliando para publicação

34. Marques Junior N. N. História do voleibol no Brasil e o efeito da evolução científica da educação física brasileira nesse esporte. Um estudo com o conteúdo revisado e ampliado. Parte 1. Lecturas Educ Fís Dep 2015;20(204):1-10.

35. Marques Junior N. Lesões no voleibol e o treinamento técnico. Rev Min Educ Fís 2003;11(1):67-75. 
36. Marques Junior N. Principais lesões no atleta de voleibol. Lecturas Educ Fís Dep 2004;10(68), 1-7.

37. Marques Junior N., Silva A. Identificando os motivos das lesões no atleta profissional do voleibol na quadra. Rev Min Educ Fís 2006;14(2):68-77.

38. Zernicke R, Whiting W. Mecanismos de lesão musculoesquelética. In. Zatsiorsky V., editor. Biomecânica no esporte. Rio de Janeiro: Guanabara; 2004. p. 397.

39. Cometti G. La preparación en el fútbol. Barcelona: Paidotribo; 2002.

40. Marques Junior N. Periodização do treino. Educ Fís Rev 2012;6(2):1-34.

41. Marques Junior N. Effect of the stretching on sport performance. Peer Res Nest 2019;1(6):1-11.

42. Carvalhal C. No treino de futebol de rendimento superior. A recuperação é... muitíssimo mais que "recuperar". Braga: Liminho; 2001.

43. Bizzocchi C. O voleibol de alto nível. $2^{\mathrm{a}}$ ed. São Paulo: Manole.

44. Santos P, Castelo J, Silva P. O processo de planejamento e periodização do treino em futebol nos clubes da principal liga portuguesa profissional de futebol na época 2004/2005. Rev Bras Educ Fís Esp 2011;25(3):455-472.

45. Matveev L. Treino desportivo: metodologia e planejamento. Guarulhos: Phorte; 1997.

46. Verkhoshanski Y. Treinamento desportivo: teoria e metodologia. Porto Alegre: Artmed; 2001.

47. Arruda M, Hespanhol J. Fisiologia do voleibol. São Paulo: Phorte; 2008.

48. Marques Junior N. Physical profile (skill time) and performance of some conditioning capacities (skill reach) of the master volleyball during the sets. EBalonmano.com Rev Ci Dep 2018; 14(3):155-166.

49. Marques Junior N. Conteúdo importante para elaboração de uma escala de prescrição da intensidade subjetiva do esforço do treino. Lecturas Educ Fís Dep 2015;20(208):1-10.

50. Marques Junior N. "Estado da arte" das escalas de percepção subjetiva de esforço. Rev Bras Prescr Fisio Exerc 2013;7(39):293-308.

51. Marques Junior N. Escala de prescrição da intensidade subjetiva do esforço do treino (PISE treino): possível evolução da psicofísica - parte 1. Rev Observatorio Dep 2016;2(2):7-51.

52. Marques Junior N. Escala de prescrição da intensidade subjetiva do esforço do treino (PISE treino): elaboração e aplicação na sessão - parte 2. Rev Observatorio Dep 2016;2(2):52-98.

53. Marques Junior N, Arruda D, Neto G. Validade e confiabilidade da escala de faces da percepção subjetiva da dor muscular do esforço físico do voleibol: um estudo durante a competição. Rev Observatorio Dep 2016;2(1):26-62.

54. Marques Junior N. Confiabilidade da escala de faces da percepção subjetiva da dor muscular do esforço físico do voleibol: um estudo no voleibol master. Rev Bras Prescr Fisio Exerc 2017;11(67):405-415.

55. Marques Junior N. Problem of the classification of the muscle soreness level with the volleyball scale. MOJ Sports Med 2019;3(2):42-50.

56. Marques Junior N. Confiabilidade da escala de faces da percepção subjetiva do esforço adaptada de Foster: um estudo no voleibol master. Rev 100-Cs 2017;3(1):29-42.

57. Marques Junior N. Mecanismos fisiológicos da fadiga. Rev Bras Prescr Fisio Exerc 2015;9(56):671-720.

58. Foster C. Monitoring training in athletes with reference to overtraining syndrome. Med Sci Sports Exerc 1998; 30(7):1164-1168.

59. Marques Junior N. Periodization models used in the current sport. MOJ Sports Med 2020;4(1):27-34.

60. Issurin V. New horizons for the methodology and physiology of training periodization. Sports Med 2010; 40(3):189-206. 
61. Marques Junior N, Barbosa O. Lesão no tendão calcâneo de um atleta de voleibol: relato de experiência. Rev Bras Prescr Fisio Exerc 2016; 10(57):29-66.

Conflito de interesse: Não teve.

Financiamento: Não teve. 


\title{
História da elaboração da periodização específica para o voleibol: uma revisão
}

\author{
Nelson Kautzner Marques Junior ${ }^{1,2}$ \\ ${ }^{1}$ Mestre em Ciência da Motricidade Humana pela UCB, Rio de \\ Janeiro, Brasil. \\ ${ }^{2}$ Membro do Comitê Científico da Revista Observatorio del Deporte, \\ Universidade de Los Lagos, Santiago do Chile.
}

\begin{abstract}
Resumo
Objetivo: Foi de explicar a história da elaboração do conteúdo teórico da periodização específica para o voleibol.

Método: O estudo de revisão foi realizado em outubro de 2019 a fevereiro de 2020 e os artigos foram coletados no Research Gate com a palavra-chave periodização específica para o voleibol ou specific periodization for the volleyball.

Resultados: Essa concepção é constituído por seis períodos. O período dos acontecimentos que ocasionaram as primeiras ideias sobre a elaboração de uma concepção de periodização para o voleibol (de 1976 a 2010) foi apresentada a vida esportiva do idealizador dessa periodização e os estudos da educação física desse pesquisador que foram importantes para gerar as primeiras ideias sobre essa periodização. O período dos primeiros estudos teóricos de uma concepção de periodização para o voleibol culminaram com um artigo escrito em 2011 e 2014. Porém, essas primeiras ideias necessitavam de mais conteúdos, ocorrendo em 2016 e 2017 o período da elaboração das escalas de percepção subjetiva (esforço e dor muscular) e da estruturação da carga de treino. O período da estruturação do treino foi em 2018 a 2020 e o autor explicou o treino com bola e a sessão física para o jogador de voleibol. O período das ideias dos estudos científicos foi em 2019 porque foi escrito uma revisão com sugestão de pesquisa para os pesquisadores conduzirem pesquisas com essa concepção.
\end{abstract}

Conclusões: A história da teoria da periodização específica para o voleibol é um importante estudo para o treinador compreender a evolução das pesquisas dessa concepção.

Palavras chaves: Voleibol, desempenho atlético, habilidade motora, lesões em atletas. 